\title{
ANÁLISE ENUNCIATIVA DAS MARCAS MODAIS PRESENTES EM CORPUS DE INTERPRETAÇÃO SIMULTÂNEA DE LIBRAS-PORTUGUÊS
}

\author{
Anderson Almeida da Silva* \\ Universidade Federal do Piauí \\ Ana Paula Lima de Carvalho** \\ Instituto Federal de Ciência e Tecnologia do Piauí
}

\begin{abstract}
Resumo: Este texto centra-se nas questões do trabalho do Intérprete de Língua de Sinais na condição de segundo enunciador da produção discursiva. Esses profissionais, no momento da interpretação, buscam recriar [atualizar] os conceitos emanados da língua fonte para a língua alvo, instaurando, assim, uma segunda instância enunciativa. O quadro teórico mobilizado situa-se na perspectiva da Linguística Enunciativa (BENVENISTE, 1989; FLORES, 2008, 2009a, 2009b, 2010) e no estudo dos modais em línguas orais e na LIBRAS. Tem-se, por objetivos, buscar as marcas deixadas pelo segundo sujeito enunciador do texto, neste caso, o intérprete, quanto ao uso de modais especificamente e analisar as escolhas desse segundo sujeito enunciador por utilizar um ou outro tipo de modal (no texto alvo), que esteja explícito ou implícito na primeira situação de enunciação (no texto fonte). Para análise, a fala de uma pessoa surda, com tempo total de 40' (quarenta minutos) que estava sendo interpretada para o
\end{abstract}

* Doutorando no Programa de Pós Graduação em Linguística do IEL/UNICAMP. Professor da Universidade Federal do Piauí. Departamento de Biologia. Parnaíba, Piauí, Brasil. Email: andersonalmeida@ufpi.edu.br

** Doutoranda do Programa de Pós Graduação em Linguística da Universidade Federal do Ceará. Membro do PROTEXTO. Professora do Instituto Federal de Ciência e Tecnologia do Piauí. Parnaíba, Piauí, Brasil. Email: professoraanapaula_phb@hotmail.com 
Português oral, foi transcrita. Após a transcrição, 6 (seis) excertos da fala total, com ocorrências de modais na língua fonte ou alvo, foram analisados. Em função das análises empreendidas, pontua-se: 1. A tendência de que a modalidade deôntica seja quase sempre interpretada como na língua fonte; 2. As escolhas interpretativas são sempre guiadas por pistas enunciativas deixadas na fala do primeiro enunciador, para as quais o intérprete deve revelar domínio de aspectos pertinentes tanto à língua fonte quanto à língua alvo; 3. Na ausência de marcas modais explícitas, os intérpretes são sensíveis às noções modais extravasadas por toda a superfície textual; 4. A omissão temporal na interpretação de modais epistêmicos de grande valor de aderência podendo funcionar como uma estratégia interpretativa e não como um falseamento da informação original; 5. A noção de "tempo de checagem", sendo proposta para recobrir o tempo (não cronológico) no qual o intérprete, após receber a informação da língua fonte, realiza sua interpretação.

Palavras-chave: Interpretação. Linguística Enunciativa. Modais. LIBRAS.

\title{
ENUNCIATIVE ANALYSIS OF MODALS IN LIBRAS- PORTUGUESE SIMULTANEOUS INTERPRETATION'S CORPUS
}

\begin{abstract}
This paper focuses on the work of the sign Language interpreter in the condition of a second speaker within the speech production. These professionals, when interpreting, they look for re-create [actualize] the emanated concepts from the source language into the target language, creating, then, a second enunciative instance. The theoretical basis is situated in the perspective of the theory of enunciation (BENVENISTE, 1989; FLORES, 2008, 2009a, 2009b, 2010) and in the study of the modals in spoken languages and LIBRAS. We aim to find what are the marks left in the discourse by the second speaker of the text, in this case, the interpreter, regarding specifically to the use of modals, and additionally, to analyze their choices for using one or other type of modal (in the target text), which might have been made explicit or implicit in the first enunciative context (source text). In order to reach these goals, sampling was composed by a transcription of a video-recorded speech of a deaf person with the length of 40' (forty minutes) that was being simultaneously interpreted into spoken Portuguese. Six excerpts from the total speech, in which modal's occurrences were attested within the source or target language, were submitted to the analysis. The main findings are: 1. the tendency of the deontic modality being almost always interpreted in the
\end{abstract}


same way of the source language; 2 . the interpreting choices are always guided by enunciative clues that are left in the speech of the first speaker, to which the interpreters must to demonstrate expertise in recognizing these language-specific aspects; 3 . in the absence of explicit modals in the speech, the interpreters appears to be sensible to the modal's notions spread by the whole text's surface; 4 . the temporal omission of epistemic modals with a high degree of certainty is understood as an interpretative strategy and not as an infidelity with the original information; 5. the term "tempo de checagem" is being proposed to cover the lack of a specific term that refers to the non-chronological time in which the interpreter, after receiving the source language information, make the interpretation available to the listeners.

Keywords: Interpreting. Theory of enunciation. Modals. LIBRAS.

\section{Introdução}

A análise a que se propõe este estudo tem sua centralidade nas questões do trabalho do Tradutor/Intérprete de Língua de Sinais (doravante, TILS ${ }^{1}$ ), como o segundo enunciador da produção discursiva $^{2}$. Assumimos, por pressuposto básico, que esse profissional, no momento da interpretação, recria [atualiza] os conceitos emanados da língua fonte para a língua alvo, instaurando, assim, uma segunda instância enunciativa.

Convém, entretanto, ressaltar que não temos por pretensão criar uma abordagem teórico-metodológica de análise das traduções ou interpretações das línguas de sinais para a língua portuguesa ou outras. Antes, é no produto da tradução ou da interpretação, como domínio parafrástico da língua, que vamos centrar reflexões, buscando marcadores gramaticais [modais], que, sob a luz da Linguística da Enunciação (BENVENISTE, 2005) determinam um maior/menor grau de envolvimento do profissional com o produto traduzido. A esse respeito, Frydrych e Surreaux (2010, p.1) afirmam: "Por isso dizemos que olhar para o intérprete como sujeito, ou seja, enquanto alguém atravessado pela linguagem, e não apenas como um ser "locutor" no mundo é reconhecer-lhe sua posição de enunciador”.

Sobre o domínio teórico da tradução em línguas de sinais, existem estudos relacionados à questão da neutralidade do ato tradutó- 
rio (METZGER, 2011; NAPIER, MCKEE \& GOSWELL, 2006). Essas análises buscam desconstruir o mito de que o tradutor não faz contribuições específicas para o produto final, sobretudo, por fazer uso de expressões carregadas de sentido, concernente aqui, ao estudo dos modais. Metzger explica, quanto a isso, que "[...] o intérprete contribui na construção discursiva, o que vai além de uma mera participação na enunciação de outros" (METZGER, 2002, p.2, tradução nossa). ${ }^{3}$

Quanto às modalidades, entendemos que estas cobrem graus distintos de envolvimento e comprometimento (LYONS, 1981[2013]) do enunciador em relação ao conteúdo proposicional da sentença que recebe a modalização. Em qualquer língua natural, é possível verificar a presença das marcas modais revelando a expressão subjetiva do sujeito enunciativo. E, ainda que as diversas línguas disponham de diferentes itens e estratégias de ajustes modais, é perceptível a presença explícita ou implícita do falante no enunciado.

Segundo Zavaglia (2002), para compreender alguns fenômenos como os que vemos, por exemplo, na atividade tradutória, faz-se necessário, não somente uma imersão cultural nos ambientes nativos das línguas envolvidas, mas, também, um estudo abrangente dessas interações linguísticas. Isso nos leva a refletir sobre a essência composicional da linguagem que nos permite aprender línguas, traduzir, passar de uma para outra em atividades diversas. Sobre a atividade tradutória, Pereira (2008, p.28, grifo nosso) afirma que: "O processo de tradução recebe muitas designações (reformulação, retextualização, conversão ou transformação), e o tradutor é encarado como um mero reprodutor de textos, uma espécie de adaptador de voltagens entre as línguas, ora alça a posição de coautor".

O termo co-autor remete-nos a um dos apontamentos de Émile Benveniste (2005) em Da subjetividade da linguagem, quando afirma que o $E u$, ao enunciar-se, institui um $T u$, ou seja, o falante instaurando um $\mathrm{Tu}$ [o intérprete] que, por sua vez, instaura um segundo $T u$ [o ouvinte, receptor da interpretação]. A essa fase intermediária do percurso, acrescenta-se a força ilocucionária do 
discurso que é entendida, a priori, em seu primeiro ouvinte-transmissor e duplicada ou arrefecida para seu ouvinte-final-receptor. O trabalho encontra-se organizado em algumas seções, seguidas das considerações finais. Tratamos com mais vagar sobre a afirmação das línguas de sinais, o quadro teórico mais geral acerca das modalidades e a verificação desse fenômeno na LIBRAS, procedemos às análises e, a respeito delas, assumimos posições.

\section{Um breve retrospecto sobre o status linguístico das línguas de sinais e sua traduzibilidade}

Não faz muito tempo que as línguas de sinais tornaram-se objeto dos estudos da linguagem. A partir de 1960, mais precisamente após a publicação da tese intitulada "Estrutura das línguas de sinais", do pesquisador americano Willian Stokoe, baseada em um estudo das estruturas fonológicas da língua de sinais americana (ASL), fora reconhecido o status linguístico das línguas de sinais no mundo. Iniciaram-se, então, as pesquisas voltadas para a descrição, gramaticalização, bem como a tradução e interpretação de/ para as línguas de sinais.

Trabalhos como os de Ferreira-Brito (1995), Felipe (1988; 1998), Quadros (1995; 1999) e Quadros e Karnopp (2004) revelamse basilares, já que essas pesquisadoras foram algumas das primeiras a advogar pela Linguística da LIBRAS efetivamente. Convém destacar que as línguas de sinais manifestam todos os fenômenos exibidos pelas línguas orais, inclusive aqueles objetos de análise da enunciação, como por exemplo a interlocução, a subjetividade, as referências (presença ou ausência dos sujeitos) e as modalidades.

Há uma gama de autores interessados em pesquisar especificamente a tradução e a interpretação de/para línguas sinalizadas de diferentes perspectivas teóricas. Esse diálogo mostra a crescente inserção das línguas sinalizadas na agenda das pesquisas dos estudos em tradução e interpretação e acentua que já é ponto pacífico 
entre os linguistas que as línguas de sinais são, de fato, inter ou intra-traduzíveis.

\section{O que é a modalidade?}

A modalidade nas línguas é sempre expressão da atitude do locutor em relação a um enunciado. A presença dos chamados modais configura o grau de envolvimento, adesão do falante em relação ao conteúdo da sentença. Então, dizer Eu acho que João saiu é menos comprometedor do que dizer Eu tenho certeza que João saiu. Ou seja, as expressões negritadas revelam diferentes graus de adesão do sujeito enunciador em relação à afirmação.

De forma mais geral, o quadro de estudos das modalidades é dividido em dois tipos: as modalidades subjetivas, nas quais o locutor exprime o grau de certeza sobre o que se assevera; e as modalidades intersubjetivas, nas quais o locutor estabelece uma relação com o interlocutor por meio do conteúdo proposicional.

A modalidade epistêmica é um exemplo de modalidade subjetiva, pois se refere unicamente ao conhecimento do locutor sobre uma determinada asserção. A essa modalidade referem-se formas tais como: achar, saber, duvidar, acreditar, não acreditar e etc. A modalidade deôntica, por sua vez, pertence ao segundo quadro, o das modalidades intersubjetivas, pois suas ocorrências estão ligadas à relação entre os sujeitos e vinculadas ao conhecimento de normas sociais. Nas palavras de Ferreira-Brito (1995, p. 156), as modalidades intersubjetivas "são forças sócio-físicas atuando no sujeito". São exemplos de modais deônticos as expressões ligadas ao domínio da obrigação em contraste com a proibição, como: precisar, obrigatório, necessário, poder, dever e etc.

Essas marcas enunciativas representam a participação do sujeito na tomada da língua para a enunciação, entendida, nessa teoria, como um momento individual e único de atualização da língua pelo uso do falante. A linguística enunciativa tem seu foco no sujeito, e , segundo Benveniste (2005), é somente através da linguagem que 
um $E u$ pode existir. Em outros termos, é na/pela linguagem que o homem se constitui.

A análise de modalidades sustenta-se no fato de que é no enunciado que aparecem as marcas de um conteúdo proposicional, do ponto de vista do sujeito falante. Alguns verbos podem exercer o papel de modalizadores, dado o fato de possuírem características polissêmicas, ou seja, pelo fato de seu sentido depender, quase sempre, do cenário enunciativo em que aparecem, como, por exemplo, dever, poder etc.. Outras classes morfológicas podem também estar relacionadas com a modalização expressa pelos sujeitos enunciadores, manifestando as marcas deixadas por eles no enunciado.

Sobre a modalização para uma teoria da linguagem (CASTILHO, Ataliba; CASTILHO, Célia, 1992a), merece destaque a referência de modo na estruturação e na interpretação semântica das sentenças. A gramática recobre duas principais abordagens sobre os componentes da sentença: o proposicional (dictum) e o componente modal, conferindo uma qualificação ao enunciado (modus).

A modalidade é entendida como uma categoria linguística que caracterizará o enunciado e que incide de forma significativa sobre uma asserção, um juízo, uma apreciação, um pedido/ordem e outros recursos linguísticos pelos quais aquele que fala expressa uma atitude relativa àquilo que se diz e ao seu interlocutor. Nesse sentido, vemos Guillaume (apud CERVONI, 1989, p.56) explicando: “[...] todo ato de expressão visa 'afetar o alocutário', e, para tanto, o locutor dispões de 'mil maneiras de dizer'. O conjunto dessas maneiras de dizer constitui a expressividade.". Isso significa que não se imaginam atos de linguagem em que a expressividade estaria ausente.

\section{Modalidades epistêmicas e deônticas em LIBRAS}

Até onde se pôde investigar na literatura da LIBRAS, Ferreira-Brito $(1990,1995)$ e Xavier \& Wilcox (2014) são os únicos a realizarem estudos específicos sobre a modalização na LIBRAS. 
A diferenças entre os trabalhos desses autores está basicamente no referencial teórico adotado para o tratamento das modalidades na LIBRAS e o objetivo dos estudos.

Ferreira-Brito foca numa descrição das unidades que se comportam como modalizadores em LIBRAS e afirma que essa língua possui léxico específico que recobre, em maior ou menor tamanho, todas as noções modais existentes para as outras línguas naturais. Já no trabalho mais recente de Xavier \& Wilcox, temos uma classificação baseada nos trabalhos de Bybee et al (1994) e Van der Auwera \& Plungian (1998), que tomam as noções modais nas línguas naturais a partir de dois conceitos mais gerais, as noções de Necessidade e Possibilidade. Ainda nesse trabalho, os autores, com base no estágio sincrônico dos sinais da LIBRAS, apontam para o possível caminho da gramaticização dos sinais modais na LIBRAS a partir de itens lexicais com sentido mais concreto, o que se confirma em suas análises.

Por questões de simplificação, optamos por nos ater à classificação e aos modelos propostos por Ferreira-Brito para recobrir as noções modais na LIBRAS. A autora afirma que o continuum dos fenômenos modais são diferentemente estruturados em línguas distintas, o que nos leva a entender que, dentro da interpretação, ao intérprete caberá a função de gradar esses modais para, então, efetuar sua escolha lexical.

Em relação aos modais epistêmicos em LIBRAS, "as construções modais verbais e adjetivas são mais comuns do que as substantivas e adverbiais" (FERREIRA-BRITO, 1995, p. 127) e esses modais podem aparecer em posição inicial ou final. Exemplos da autora: EU PENSAR VOCÊ CERTO ou EL@S NOIV@ ÓBVIO 4 .

A modalidade alética também é mencionada como sendo um tipo de modalização polissêmica, pois podem manifestar-se epistêmica ou deônticamente. Diferente da modalidade epistêmica por excelência, a alética recobre o campo das verdades verificáveis, como, por exemplo, fenômenos naturais ou outros. Nesse caso, Ferreira-Brito (1995) afirma que modais epistêmicos do tipo IMPOSSÍVEL e NÃO-ACREDITAR podem adquirir um valor alé- 
tico. Vejamos os exemplos que oferece: NÃO-PODER RECIFE NEVE ou ÓBVIO ESTA PLANTA MORRER.

Por fim, a modalidade deôntica é mencionada como o grupo das noções de possibilidade, permissão e obrigações, como já fora explicitado. Itens lexicais como PRECISAR, OBRIGATÓRIO (substantivo/adjetivo), PODER, PROIBIDO (adjetivo/verbo), TERQUE, DEIXAR, OPICIONAL recobrem essa noção deôntica na língua. A autora separa os contextos em que os modais deônticos podem ocorrer como oriundos de obrigações internas ou externas ao locutor, como nos exemplos, sucessivamente: OPICIONAL! (você é que sabe!) ou OBRIGATÓRIO REUNIÃO (você precisa obrigatoriamente vir à reunião).

Muitos dos modelos desenvolvidos para a análise de modalidade, como o quadrado de Apulée e o hexágono de Kalinowski (1976, p.13-14 apud FERREIRA-BRITO, 1995, p. 144), não eram compatíveis com as noções modais para a LIBRAS pela ausência de fronteiras claramente marcadas entre as noções modais. Então, era necessário decidir quando um locutor expressa que tem total certeza sobre a sua asserção ou quando ele não tem total certeza sobre o fato. Muitas vezes, por exemplo, somente o sinal lexical CERTO seria insuficiente para demarcar tais limites.

Ferreira-Brito (1995) afirma que as línguas naturais são marcadas pelo dinamismo, gradação e superposição com que tratam suas fronteiras modais, ou seja, PROVÁVEL e POSSÍVEL podem se superpor em alguns contextos nos quais tenham iguais significados ou ser distintos nos contextos em que um dos dois é mais apropriado. Daí as noções de Bacia(B) e vizinhança (v), apresentadas pela autora para dar conta de construções modais em qualquer língua natural, conforme segue a figura 1 abaixo: 


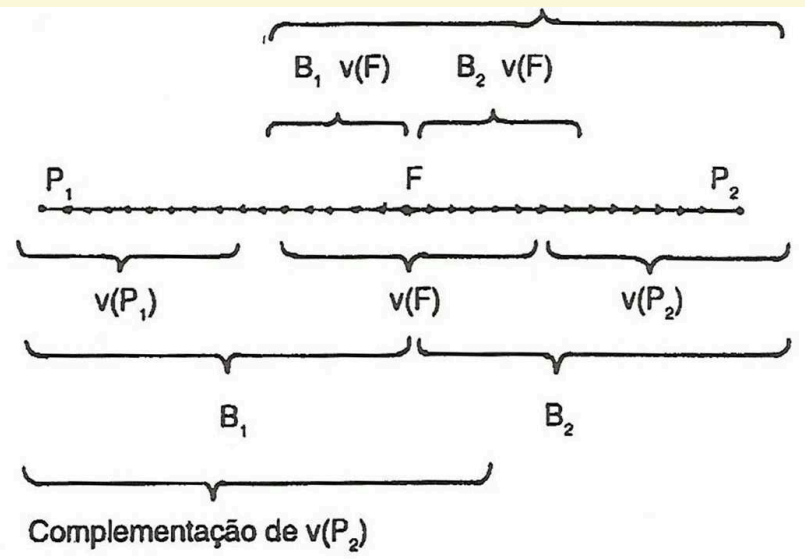

Figura 1. Modelo lógico-topológico de modalidade (FERREIRA-BRITO, 1995, p. 147).

Grosso modo, Ferreira-Brito demonstra que, em dados momentos, as noções modais extravasam os contextos nocionais, área de bacia, ou são limítrofes a outros conceitos justapostos, regiões de vizinhança. Após efetuar as análises para as noções modais em LIBRAS, a autora assevera: “A LIBRAS apresenta menos itens lexicais modais do que o Português, mas desenvolveu um mecanismo de matizar os sinais modais, alterandolhes os movimentos para mais ou para menos fortes" (FEREIRA-BRITO, 1995, p. 148). E acrescenta, sob a análise de uma metáfora orientacional, que, em contextos deônticos, os sinais parecem apresentar-se muito mais focados na mão dominante e no movimento enérgico do locutor. Por outro lado, para os modais epistêmicos, os movimento não são enérgicos e a cabeça é o principal ponto de articulação. Valemo-nos dessas afirmações para as análises que seguem sobre a ocorrência de modais em corpus de interpretação da LIBRAS. 


\section{Benveniste e o quadro metodológico da enunciação}

Para Benveniste, a enunciação supõe a conversão individual da língua em discurso. O autor não utiliza a expressão gramática da enunciação, por defender a não existência de uma gramática inteiramente enunciativa. $\mathrm{O}$ enfoque recai sobre as possibilidades de construção de sentido da língua em uso em situação de enunciação ${ }^{5}$.

É na interação comunicativa que surgem as marcas da enunciação, utilizando o que Benveniste denomina de Aparelho formal da enunciação, quando, por um ato individual de expressão, o sujeito atualiza a língua. A análise que empreendemos neste estudo segue no sentido da exposição de Flores e Teixeira (2010, p.106):

[...] todo e qualquer fenômeno linguístico carrega em si a potencialidade de um estudo em termos da enunciação, já que sua existência depende do sujeito que o enuncia. $\mathrm{O}$ objeto linguístico da enunciação é todo o mecanismo linguístico cuja realização integra o seu próprio sentido e que se autorreferencia no uso. A enunciação é, pois, o que constitui esse processo.

Tem-se, portanto, como fundamental, na construção de um trabalho baseado na descrição lingüística, que se assuma, conforme Benveniste, o "jamais dado", compreendido como a irrepetibilidade da produção enunciativa. Nessa perspectiva, nos dados oriundos da interpretação, como é o nosso corpus, é complexo entender a relação entre a primeira enunciação na língua fonte, da palestrante, e a segunda enunciação na língua alvo, da intérprete. Focalizamos,então, as relações biunívocas observadas na instância dos dados que ocorrem em ambos os enunciados, primeiro e segundo, observando o que se mantém e o que se altera em função da tradução. 


\section{Do corpus e da transcrição}

O corpus constituinte desta análise é fruto da atividade interpretativa de uma TILS proficiente em LIBRAS, o que indica a competência do profissional para esse exercício e garante maior confiabilidade ao material transcrito, fruto da interpretação sinal -oral ${ }^{6}$. Destacamos, aqui, a autorização dos atores da interpretação para efetuarmos esta análise, ainda que para este tipo de análise seja necessário o uso da imagem dos sujeitos. Ademais, o vídeo ${ }^{7}$ está integral e publicamente disponível no Youtube.

Utiliza-se a denominação de sujeito enunciador 1 (SE1) para a palestrante que sinaliza em LIBRAS e de sujeito enunciador 2 (SE2) para a intérprete. Utilizaremos essa notação durante as análises, já que se pretende efetuar uma comparação entre o texto fonte produzido pelo SE1 e o texto produzido pelo SE2 durante a interpretação simultânea.

Os dados são definidos como excertos de uma filmagem da interpretação da fala $^{8}$ de uma surda com nível de doutorado em palestra pública e foram transcritos para a língua portuguesa seguindo algumas recomendações teórico-metodológicas de Flores (2006, p.74 apud FRYDRYCH, 2010), quais sejam: "Transcrever é condição de análise empreendida em linguística, sendo até mesmo uma etapa da análise; A transcrição [...] pode ser estendida a estudos de diferentes corpora; Cada transcrição é sempre única, singular e não linearmente extensível: é o efêmero da enunciação [...]".

O sistema de transcrição escolhido para a análise de dados está disponível em forma de nota e fora indexado em um momento anterior neste mesmo texto.

\section{Análise dos dados}

As alterações sofridas pelos sinais durante a fala da pessoa surda são percebidas pelo profissional intérprete e, consequentemente, traduzidas através de itens lexicais específicos na língua alvo. Fica 
a cargo do intérprete escolher, dentro do repertório disponível, o verbete que mais se aplica à situação de enunciação. Quanto maior for a alteração sofrida pelo sinal em LIBRAS, mais categórico ou mais fraco será o conceito modal (FERREIRA-BRITO, 1995).

Destacamos que a análise não se encontra, em nenhum momento, ligada ao curso interpretativo da realização do sinal até a vocalização do intérprete. Antes, volta-se para a intenção de se aclararem as questões relacionadas às diferentes estratégias de modalização utilizadas pelos intérpretes, considerando as línguas de diferentes modalidades ${ }^{9}$.

Nosso foco são as escolhas do SE2 por um ou outro tipo de modal, que esteja explícito ou implícito na situação de enunciação. Ou seja, é importante entender como os comportamentos do intérprete em relação ao conteúdo da sentença podem recair em alguns termos como os modais. Essas informações são relativamente rígidas e, por isso, não podem ser aleatoriamente traduzidas ou, em outros termos, reconfiguradas. Isso porque a tarefa de dizer é individual e subjetiva e o intérprete, ao redizer, 're-marca' esse enunciado utilizando gradações modais que são frutos da sua interpretação. Entende-se, aqui, o termo interpretação nos contextos de tradução e como fruto de uma atividade cognoscível dos quais se depreende uma abstração para sua efetivação. Não se está julgando a (im)propriedade das escolhas lexicais feitas pelo intérprete, visto que uma análise desse tipo estaria situada em outra perspectiva de investigação, que não a análise a que nos propomos.

Toda a fala traduzida soma quase 40 minutos de interpretação na versão de língua de sinais para a língua oral. Entretanto, foram transcritos para análise apenas alguns excertos da exposição, conforme seguem: 


\section{Excerto 1}

\section{SE1 - PALESTRANTE - LIBRAS:}

EXEMPLO BRASIL PORTUGUÊS É LÍNGUA OFICIAL MAS PRECISAR RESPEITAR LÍNGUAS GRUPOS OUTR@S LÍNGUAS INDIOS TER MAIS DO-QUE OUTRAS LÍNGUAS ÍNDIOS TEM GRUPOS FAMÍLIAS DESCENDÊNCIA EUROPA VIR ALEMANHA ESPANHA SUL VÁRIAS LÍNGUAS BRASIL TER VÁRIAS OFICIAL PORTUGUÊS NÃO VÁRIAS LÍNGUAS/ LIBRAS PRINCIPAL TAMBÉM GRUPO LINGUÍSTICO

\section{SE2 - INTÉRPRETE - PORTUGUÊS:}

Por exemplo, nós temos a língua oficial do Brasil, mas, é preciso que sejam respeitadas as outras línguas que são também utilizadas neste país como as línguas indígenas, como as línguas faladas pelos imigrantes, pelos imigrantes europeus e de vários outros cantos do mundo que chegaram ao Brasil. E, várias outras línguas que são faladas e utilizadas no país assim como a língua de sinais.

No excerto 1, percebe-se a tendência de que, para a modalidade deôntica, ela seja quase sempre interpretada como na língua fonte. Não há estratégias específicas percebidas pela atuação do intérprete neste contexto. O SE1 ao dizer "MAS PRECISAR RESPEITAR LÍNGUAS” tem o mesmo valor modal da informação interpretada em "mas, é preciso que sejam respeitadas as outras línguas". Em alguns casos, observa-se um comportamento de monitoramento estilístico do TILS que pode utilizar-se de "dever", "cabe à..." ou outros registros mais ou menos formais. 


\section{Excerto 2}

\section{SE1 - PALESTRANTE - LIBRAS:}

MAS EXEMPLO GRUPO SURD@ OPINIÃO+ + GRUPO CEG@ OPINIÃO GRUP@ GRUP@ GRUP@ OPRESSÃO OPRESSÃO OPRESSÃO ${ }_{\mathrm{Me}}$ OPRESSÃO $I-D-A$ RESPEITAR [PAUSA] SURD@ QUER $^{\text {EXP. INTERROGATIVA ASSIM COLOCAR }}{ }^{\text {EM-LISTA }}$ VOC@ QUERER CEGO QUERER COLOCAR ${ }^{\text {EM-LISTA }}{ }_{\mathrm{i}}$ APRESENTAR ${ }_{\mathrm{k}}$ LÁ $O-N-U$ MAS TRISTE EXPRESSÃO FACIAL. LAMENTO ${ }^{\mathrm{j}} \mathrm{O}$-QUE BRASIL TER ALGUNS GRUPOS OPRESSÃO GRUPO OPRESSÃO OPRESSÃO EXEMPLO EU PESSOA LIGAR OPINIÃO O-QUE EXPRESSÃO FACIAL. INTERROGATIVA SURD@ MAS [...]

\section{SE2 - INTÉRPRETE - PORTUGUÊS:}

“...então, nessa discussão, as várias deficiências, elas opinam em pé de igualdade a respeito de suas próprias demandas $e$ reivindicações, as pessoas cegas com suas reivindicações, as pessoas surdas, enfim, as várias deficiências, e nenhuma das opiniões se sobrepõem as outras... infelizmente, no Brasil não é isso que percebemos".

Nesse caso, pode-se observar a função do intérprete de modalizar o adjetivo triste referindo-se à apreciação do locutor sobre o conteúdo enunciado. O SE1 sinaliza "TRISTE ${ }^{\text {EXPRESSÃo FACIAL. }}$ LAMENTO" e o intérprete sinaliza como "infelizmente". Confirmase, aqui, a proposta de Ferreira-Brito (1995), para quem línguas diferentes divergem em suas semânticas lexicais, carregando aspectos idiossincráticos de suas palavras. Nesse sentido, cada língua pode ter certo nível de vagueza, ou seja, para que se complete seu sentido, outras informações precisam coocorrer quando de sua enunciação. O mesmo poderia acontecer em uma interpretação no 
sentido inverso, em que itens lexicais do Português não encontrassem equivalentes para as mesmas noções em LIBRAS.

Observa-se a autonomia da marca não manual expressa em sobrescrito "EXPRESSÃO FACIAL. LAMENTO", que não pode ser tratada como um simples traço suprassegmental do sinal. Antes, a expressão facial de lamento indica um processo de derivação do sinal TRISTE, naturalmente um adjetivo em LIBRAS, para o advérbio INFELIZMENTE. A interpretação que se tem da primeira enunciação é a de que algo lhe causa tristeza. No contexto da tradução, algo é triste ou lamentável, por isso, a escolha de infelizmente.

Para os fins desta análise, é importante pontuar que as escolhas interpretativas são guiadas pelas marcas enunciativas deixadas na fala do SE1. Essas marcas são pistas linguísticas para a construção do segundo enunciado pelo intérprete. "Infelizmente", nesse contexto, funciona como uma modalidade apreciativa, embora o item lexical "TRISTE" na fala do SE1 não carregue, em LIBRAS, por si só essa denotação. Acredita-se, ainda, na primazia da função linguística da expressão facial como um morfema gramatical para o nível morfológico, o que significa que uma expressão facial pode alterar o valor da palavra ou possibilitar a formação de uma outra instância lexical ${ }^{10}$.

Mecanismos de modalização como esses, nos quais o valor modal está concentrado em itens que tem, a priori, funções prosódicas e não lexicais, como as expressões faciais, são bastante produtivos para línguas orais do mesmo modo. Algum falante de Português pode dizer "infelizmente, no Brasil não é assim" ou modificar sua prosódia para algo pausado e mais longo, como: "inn-fee-liz-mente no Brasil não é assim”, indicando também uma gradação no nível da modalização apreciativa desejada. As diferenças entre o contexto enunciativo 1 (língua de sinais) e o contexto 2 (língua oral) é que a prosódia por si só, nesta última, não pode encabeçar uma instância lexical, enquanto que nas línguas de sinais, $\operatorname{sim}^{11}$. 


\section{Excerto 3}

\section{SE1 - PALESTRANTE - LIBRAS:}

PESQUISAR CONTRA ISTO PODER-NÃO ACIMA PRINCIPAL CONVENÇÃO $O-N-U$ PORQUE CONVENÇÃO $O-N-U$ ACIMA MUNDO [PAUSA] MAS EXEMPLO TER TRADUÇÃO ERRADA CONVENÇÃO $O-N-U$ TRADUÇÃO ERRADA CONVENÇÃO $O-N-U$ FOCO +++ MAS POLÍTICA ENSINAR TRADUÇÃO ERRADA ISTO-IX(CONVENÇÃO)MOTIVO FAZER POLÍTICA JEITO DEL@

\section{SE2 - INTÉRPRETE - PORTUGUÊS:}

"[...] como muitos apregoam que a questão da cultura surda é uma questão ideológica, não, isso está presente num documento internacional, reconhecido internacionalmente, infelizmente, existem interpretações equivocadas, distintas deste documento. A convenção ela parece ser bem clara, mas, infelizmente, ainda existem nas políticas educacionais outras interpretações divergentes do que seja, então, a cultura surda e essa identidade cultural e linguística dos surdos".

No excerto 3, não há marca modal avaliativa aparente na enunciação do SE1, nem de ordem lexical ou por recursos prosódicos, como explicitado no excerto anterior. É sabido que, durante uma interpretação simultânea, não há tempo hábil para se julgarem todas as (im)propriedades das expressões selecionadas para a tradução que se efetua. No entanto, se o SE2 utiliza a palavra infelizmente, é porque certamente há indícios de que essa modalização esteja extravasada por toda a superfície textual, ou seja, sem marcas modais explícitas, aparentemente homogêneas em ambas as instâncias.

Esse tipo de modalização pode ocorrer de forma instintiva, mas, não imotivada. O intérprete, ao traduzir, efetua uma inferência sobre o tipo de modalidade mais adequada, já que assume também o 
papel de SE2. Olhando para a fala do SE1, a repetição dos blocos em negritos parece funcionar como pontos satélites em que se pode encontrar a marca apreciativa. Pela repetição da expressão "TRADUÇÃO ERRADA" na fala do SE1, o SE2 reavalia a posição do SE1 em relação ao conteúdo da sentença, ou seja, SE1 parece lamentar, entristecer-se com a forma sob as quais as políticas são desenvolvidas em certos contextos.

\section{Excerto 4}

\section{SE1 - PALESTRANTE - LIBRAS:}

VERDADE ISSO SÓ SUPERIOR FACULDADE NÃO SUPERIOR FACULDADE SÓ FOCO ENSINO BÁSICO QUAL EXPRESSÃo FACIAL INTERROGATIVA BÁSICO CRIANÇAS SURD@S EXPRESSÃO FACIAL $^{-}$ INTERROGATIVA JOVENS CRIANÇAS JOVENS CRIANÇAS SURD@S

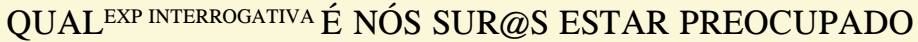
ESTES-IX $_{M d / M e}$ ENSINAR BÁSICO ESTES-IX PIOR ${ }^{\text {ASPECTO }}$ CONTINUATIVO MOTIVO ESTA POLÍTICA MEC COMBINAR-NÃO

\section{SE2 - INTÉRPRETE - PORTUGUÊS:}

"vemos um grande investimento no ensino superior, sim, mas fica aquém esse investimento na educação básica dos surdos, e, essa é a nossa preocupação, percebemos uma defasagem e não concordamos grande parte com a atual política do MEC"

No excerto 4, o sinal de "VERDADE" em LIBRAS (FERREIRA-BRITO, 1995) funciona como um modal epistêmico que configura o grau de adesão do locutor com o que se fala e diz diretamente do conhecimento do enunciador sobre o dito. Na interpretação fornecida pelo SE2, não há ocorrência de nenhum modal com valor epistêmico parecido com o valor de "VERDADE". Ressal- 
ta-se que na interpretação simultânea, como decorrente da função de traduzir, também se intercorrerá da função de se semantizar a língua, resignificando-a. Por isso, as escolhas do SE2 orientam-se a seu tempo; do contrário, não teríamos uma segunda instância enunciativa.

$\mathrm{Na}$ fala do SE2 "sim" pode funcionar com uma modalidade epistêmica uma vez que se poderiam intercambiar as formas de dizer: "É verdade que ela saiu" ou ainda "Sim, ela saiu". Independente do grau de comprometimento que uma ou outra palavra pode expressar no contexto, é relevante perceber como o intérprete grada essa percepção modal, especificamente em contextos de interpretação interlingual/intermodal ${ }^{12}$.

\title{
Excerto 5
}

\section{SE1 - PALESTRANTE - LIBRAS:}

\author{
LETRAS-LIBRAS MOTIVO DECRETO 5626 IX(DECRETO) \\ EXPRESSÃo FACIAL AFIRMATIVA É DISCUTIR NOV@ BRASIL PODER \\ EL@ (SINAL-DA-PESSOA) FALAR VERDADE CERTO \\ DESENVOLVER PRESENTE-PESSOA-CL MOTIVO LETRAS- \\ LIBRAS DISCIPLINA LIBRAS GERAL BRASIL CERTO $_{\text {Md/Me }}$
}

\section{SE2 - INTÉRPRETE - PORTUGUÊS:}

“[...] Letras LIBRAS, este instituído muito em função do decreto 5.626 mencionado anteriormente, mencionado tanto pela (nome da pessoa), quanto pela (nome de outra pessoa), de fato, a LIBRAS tem se difundido amplamente no país por causa dos cursos de Letras LIBRAS instituídos e também temos boas perspectivas de muitas vagas para $[. .$. 
No excerto, há três pontos críticos em relação ao emprego de estratégias modais que dizem respeito diretamente às estratégias empregadas pelo intérprete para modalizar a sentença, aparentemente com a função de amenizar a sua adesão ao primeiro dito pelo SE1. É importante ter em mente que a tarefa de interpretar simultaneamente causa reações imediatas na audiência ouvinte. Por isso, parece-nos mais comum que intérpretes procurem por formas cada vez menos comprometedoras, não por questões de infidelidade, mas numa tentativa de equilibrar as pressões laterais causadas pelo léxico de uma língua ou de outra.

É necessário compreender, dentro da função de intérprete, sobre o que dizer e como dizer, considerando contextos culturais e linguísticos. Somente o intérprete sabe a força que cada expressão desempenha na língua fonte ou na língua alvo. Quanto a essa questão, percebemos, na interpretação em análise, o apagamento estratégico de algumas expressões, ou de contextos modais pouco explícitos, com pistas insuficientes para que o intérprete reproduza a informação da forma mais fidedigna possível.

O primeiro modal em negrito, "PODER", do SE1, funciona como uma modalidade alética, pois não está em jogo uma atitude da ordem da necessidade ou da obrigação, mas de uma verdade verificável de que o decreto a que se refere o locutor pode, de fato, ter trazido benefícios. O intérprete, já ciente da resposta que está posta em verificação pelo modal alético, apaga-o, presumindo a sua verdade na sua interpretação. Do contrário, acreditaríamos que o intérprete lançaria mão de uma pergunta retórica ou de outras estratégias para deixar em aberto a intencionalidade de SE1 ao utilizar esse modal.

A segunda ocorrência diz respeito a dois modais que são executados em sucessão pelo SE1: "VERDADE CERTO são modais epistêmicos que dizem sobre a verdade de um enunciado específico. Contrariamente ao que se espera, a justaposição dos sinais de VERDADE e CERTEZA - este último realizado, inclusive, com as duas mãos (direta e esquerda), o que lhe intensifica a interpretação - não é realizada pela intérprete SE2. Nesse caso, 
como a seleção de um modal de alto comprometimento impossibilitaria uma retomada ou correção sobre a afirmação, há uma elisão deste componente. Isso se dá, provavelmente, por força das estratégia tempo de checagem, que descreveremos com mais detalhes na análise do próximo excerto.

A terceira ocorrência de CERTO não diz respeito a uma modalização, já que na LIBRAS os modais epistêmicos também podem ocorrer em posição final (FERREIRA-BRITO, 1995) como em: EL@S-2 CASAR, CERTO ${ }_{M d / M e}$ (Tenho certeza que eles são casados), mas, neste contexto certo é um adjetivo que pode ter sua significação aproximada em: "temos boas perspectivas", pelo SE2.

\title{
Excerto 6
}

\section{SE1 - PALESTRANTE - LIBRAS:}

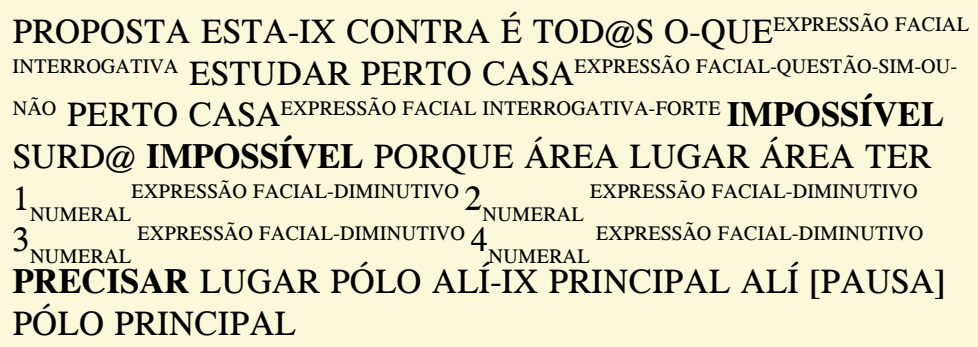

\section{SE2 - INTÉRPRETE - PORTUGUÊS:}

\begin{abstract}
"Esta proposta de uma educação para todos, de colocar as crianças numa escola mais próxima de casa, infelizmente, para os surdos não é a melhor proposta. É impossível que seja a melhor proposta. Por quê? Porque existem um, dois ou três surdos no mesmo bairro, por que não criar unidades polo? Escolas-polo? Pra atendimento dessas crianças?".
\end{abstract}


Esse último excerto da análise demonstra mais claramente o que acontece numa interpretação simultânea, recortando especificamente o quadro do uso de modais em diferentes instâncias enunciativas. Na exposição teórica, vimos que o uso das modalidades na língua revela as marcas que delatam a posição do sujeito enunciador em relação ao que está sendo dito. Há a orientação de que o intérprete, como segundo enunciador, realoque-se para a posição do sujeito. Não entraremos nas questões relativas à contribuição do intérprete para o produto final da interpretação, pois acreditamos estar clara no corpus selecionado a presença do SE2 somada à fala do SE1.

Julgamos pertinente, neste ponto, apontarmos um comportamento de amenização, suavização do conteúdo original ao invés de considerarmos uma (possível) tentativa de neutralização do primeiro enunciado em relação ao segundo. Sobre a neutralidade da figura do intérprete, Daniel Gile (1995b apud GILE, 2001) desconstrói este mito em termos práticos com a fórmula: Texto Alvo $=\mathrm{M}+$ $\mathrm{FI}+\mathrm{LII}+\mathrm{PI}^{13}$.

Se alguém assevera a impossibilidade, como o SE1 o faz como o sinal "IMPOSSÍVEL", na sentença: "IMPOSSÍVEL SURD@ IMPOSSÍVEL", do excerto 6 acima, o intérprete não poderia fugir para outra região de modalização que não fosse algo que está na fronteira da noção de impossibilidade. Mas, se aplica à prática interpretativa, mais especificamente à interpretação simultânea, a noção que denominaremos de tempo de checagem. O termo tempo de checagem refere-se ao percurso entre o momento em que o sinal é proferido e o intérprete concentra-se em buscar sua posição nas fronteiras do significado. Do ponto de vista enunciativo, o sentido é recriado durante a enunciação, e a língua é atualizada. Sendo assim, nem sempre impossível quer dizer "impossível". O fenômeno enunciativo contempla, em si mesmo, o deslocamento das funções de palavras, entendendo-o como uma permissão do sistema.

Nessa perspectiva, o que denominamos aqui como tempo de checagem parece não apresentar correlatos em outros pontos de vista teóricos, por não se tratar especificamente da performance do intérprete (delay, palavras por minuto, fluidez e etc.), mas do 
momento em que o intérprete permite-se exercer sua subjetividade, trazendo à cena a sua posição de locutor, realizando a traduzibilidade do texto.

No tempo de checagem, o SE2 opta pela utilização de um modal avaliativo: "infelizmente", para a palavra "IMPOSSÍVEL". Nesse caso, há uma clara distorção do conteúdo modal da impossibilidade vislumbrada pelo SE1, o que, para uma teoria interpretativa, pode ser entendido como uma estratégia de modalização, que pode ser inclusive guiada por questões culturais ou de perfil da audiência. O que não nos escapa é a percepção de que o SE2 participa efetivamente da reconstrução do enunciado do SE1, modulando, gradando ou amenizando esse conteúdo. Essa suavização imposta à sentença pela atitude exclusiva do SE2 testemunha a complexidade de se lidar com os sistemas modais quando da interpretação, pois não há escalas formais ou outras maneiras de mensurar o que se quis dizer, a não ser a obrigatoriedade de se dizer uma segunda vez. Dizer que é impossível está no limite da escala sobre o conhecimento de um fato, pois apaga completamente qualquer outra possibilidade de retomada do conteúdo. Para fugir dessa não possibilidade futura, no tempo de checagem, o SE2 ameniza para trabalhar melhor, como alguém que lida com uma massa e a deixa descansar para melhor moldá-la a seguir. O tempo de checagem é o tempo do descanso da massa, na metáfora da 'massa da informação'.

$\mathrm{Na}$ interpretação simultânea, deve-se ter em mente que a informação não está disposta de forma indefinida, ou seja, qualquer noção de tempo na interpretação é ligeira. Vemos que, em outra operação, o SE2 retoma a noção de impossibilidade, quando diz: $E$ impossivel que seja a melhor proposta. Então, vejamos a diferença na sequência em contraste: "infelizmente, para os surdos não é a melhor proposta" e "É impossivel que seja a melhor proposta". Ao término do tempo de checagem, conferido pelo SE2 que aquele conteúdo não poderá estar mais comprometido e de que uma nova ideia não está por surgir, ele, finalmente, usa o modal de maior força. Sumarizando, intérpretes parecem utilizar modais de menor força sempre que suspeitam de que a informação não exija tanta 
força ilocucionária. Após o tempo de checagem, podem operar com restituições que não tem nenhum prejuízo para a língua alvo, como vimos nesta análise.

Por último, o SE1, ao dizer da necessidade de se implementar escolas-polo para os surdos, claramente enunciado em PRECISAR LUGAR PÓLO, expõe o SE2 a uma modalidade deôntica. O SE2 reavalia o conteúdo e apaga a marca modal na sua interpretação, isto é, não há mais a força do dever que instaura uma relação intersubjetiva de ordem ou pedido, mas a informação aparece traduzida em questões retóricas, que convidam (afetam o interlocutor) a uma reflexão. Não deixa de cumprir os requisitos para que se tenha, de fato, uma noção deôntica ocorrendo, quando diz: "Por quê? Porque existem um, dois ou três surdos no mesmo bairro, por que não criar unidades polo? Escolas-polo? Pra atendimento dessas crianças?".

\section{Conclusão}

A enunciação apresenta-se como o campo do múltiplo, e não do unívoco. A aplicabilidade do que se pode denominar de linguística enunciativa está fundamentada nos pilares dessa nova maneira de se conceber a língua. Entender a tradução como uma instância enunciativa que recria, atualiza a língua quando de sua utilização e, a partir daí, estabelece-se um novo olhar sobre a língua em uso, objeto que por muito tempo esteve fora das discussões do campo linguístico.

Nesse sentido, as modalidades revelam-se como um desafio e um conteúdo caro ao intérprete, na tarefa de mensurar a noção modal apresentada na língua fonte e de reproduzi-la na língua alvo, o que incide, inclusive, na discussão das estratégias explicitadas neste texto (a saber: tempo de checagem, amenização, apagamento, gradação modal e ressignificação de conteúdos) em cursos de formação de intérpretes de línguas de sinais, como é o caso específico.

Vimos que os modais se apresentam como ferramentas da linguagem que garantem a funcionalidade de certas operações dis- 
poníveis no aparato linguístico. E, no tocante à tarefa do intérprete de re-significar pela atividade enunciativa, esse profissional se refugia, muitas vezes, em redistribuir no tempo de checagem a fala de outrem, utilizando, também, a estratégia modal. Propomos, para futuras análises de interpretação simultânea, que essa noção, entendida não em padrões cronológicos, mas como uma operação de conscientização para a cognição, da seleção e da redistribuição, seja mais amplamente explorada.

Acreditamos que muitos pontos aqui discutidos estendam-se também a outros contextos traducionais em que haja dois ou mais sujeitos enunciadores, ainda que, para esse caso de tradução interlingual e intermodal, muitos aspectos ainda careçam de descrição. A análise do dito é, evidentemente, fundamental, para que nas suas entrelinhas, descubramos o sentido da enunciação. Mas, o fato é que agora buscamos novas maneiras de se reflexionar sobre o dizer e não somente sobre o dito.

\section{Notas}

1. Na literatura dos Estudos da Tradução de/para línguas de sinais é comum se utilizar a denominação TILS para tradutores e intérpretes, pois, embora sejam atividades distintas, a maioria dos tradutores de línguas sinalizadas estão envolvidos com a interpretação simultânea e não a tradução de textos e outros registros especificamente. Nossa análise tem o foco na atividade interpretativa, por isso a sigla TILS deve ser tomada genericamente, embora estejamos nos referindo especificamente ao intérprete neste texto.

2. Tomamos "discurso" nos termos de Benveniste como: a atualização da língua cada vez que alguém assume o lugar de eu (BENVENISTE, 2005).

3. No original: “(...)the interpreter makes contributions to the discourse that extend beyond mere renditions of other participants utterances." 
4. Utilizamos a proposta de transcrição de dados de línguas de sinais apresentada por Felipe (2005). As glosas utilizadas em trabalhos de pesquisa em línguas de sinais são bastante similares na maioria dos estudos feitos na área, o que facilita a compreensão. Resumidamente, apresentamos aqui alguns critérios apresentados pela autora para a transcrição: 1.sinais são transcritos com letras maiúsculas, Ex: CASA; 2. Sinais simples em LIBRAS que sejam traduzidos por mais de uma palavra em Português são transcritos com o auxílio da hifenização, Ex: CORTAR-COM-FACA; 3. Sinais compostos são transcritos conforme segue: Ex: CAVALO^LISTRA = Zebra; 4.Datilologias são representadas com letras separadas por hífens, Ex: A-N-A; 5. Sinais soletrados, ou seja, palavras da língua oral que por empréstimos são incorporados à língua de sinais estão representados em itálico, Ex: $N-U-N-C-A ; 6$. Sinais neutros para gênero e número são transcritos com a @, Ex: AMIG@; 7. Os traços não manuais e outras informações prosódicas (suprassegmentais) são feitos em sob ou subescrito; 8 . Verbos recebem os índices ( $\mathrm{i}=$ ponto próximo à $1^{\mathrm{a}}$ pessoa, $\mathrm{j}=$ ponto próximo à $2^{\mathrm{a}}$ pessoa, $\mathrm{k}=$ ponto próximo à $3^{\mathrm{a}}$ pessoa, e $=$ esquerda e $\mathrm{d}=$ direita) para concordância de lugar e $(1 \mathrm{~s}, 2 \mathrm{~s}, 3 \mathrm{~s}$ - para $1^{\mathrm{a}}, 2^{\mathrm{a}}$ e $3^{\mathrm{a}}$ pessoas do singular e $1 \mathrm{p}, 2 \mathrm{p}$ e $3 p$ para $1^{\mathrm{a}}, 2^{\mathrm{a}}$ e $3^{\mathrm{a}}$ pessoas do plural) para concordância número-pessoal; 9 . Repetição do sinal é representado pelo + e 10. Quando um sinal é realizado somente por uma mão ou pelas duas há a indicação de $\mathrm{md}=$ mão direita e me =mão esquerda.

5. Diferindo de outras posturas teóricas, o quadro enunciativo reclama condições específicas para sua efetivação, como o par eu/tu, o espaço e o tempo (FLORES et al, 2009a).

6. Modalidade de tradução na qual o intérprete ouvinte vocaliza as informações sinalizadas pelo falante surdo(a).

7. Os vídeos podem ser encontrados com os nomes Audiência Educação Inclusiva Patrícia, partes 1 e 2.

8. A fala é vista, aqui, na concepção, por exemplo, de Flahaut (1979: 11-75 apud FLORES et al, 2009b,p.119), quando afirma ser "o entrecruzamento das coerções simbólicas da língua e das forças ideológicas do discurso", fugindo do conceito de fala da perspectiva fonadora e biológica, visto que estamos tratando de um sujeito surdo.

9. Modalidade, aqui, não se refere à marca enunciativa do sujeito que está sendo explorada no trabalho, mas à modalidade visual-motora, no caso da LIBRAS e modalidade oral-auditiva no caso da língua portuguesa. Em contraste com o con- 
ceito homônimo, "modalidade", utilizado ao longo deste texto.

10. Cf. Herrmann e Steinbach (2013), sobre marcas não manuais em línguas de sinais.

11. Este fato pode encontrar-se relacionado à gramaticalidade da unidade 'gesto'. Outras pesquisas são fundamentais para a elucidação desse fenômeno.

12. Para além de serem línguas distintas, a LIBRAS e o Português são línguas de diferentes bases semióticas e substâncias fonológicas. Pesquisas futuras devem dizer se existem efeitos dependentes da modalidade de produção das línguas para a tradução. Nossa hipótese é de que há efetivamente essas diferenças no modus operandi dessas interpretações.

13. M é a mensagem disposta no núcleo da informação, FI (Framing Information) - Informação contextualizadora, LII (Linguistically induced information) - Informação motivada por questões linguísticas e PI (personal information) - Informações pessoais, decorrentes do background do intérprete.

\section{Referências}

BENVENISTE, Émile. Problemas de linguística geral I. Trad. Maria da Glória Novak; Maria Luisa Neri. Ver. Isaac Nicolau Salum. 5.ed. Campinas, SP: Pontes, 2005.

CASTILHO, Ataliba, T.; CASTILHO, Célia Maria M. de. Advérbios Modalizadores. In: ILARI, Rodolfo (Org.) Gramática do Português Falado. Vol. II. Campinas: Editora da Unicamp, 1992. p. 213-260.

CERVONI, Jean. A enunciação. Trad: L. Garcia dos Santos. São Paulo: Ática, 1989. 
FRYDRYCH, Laura Amaral Kümmel; SURREAUX, Luiza Milano. Transcrição de LIBRAS na perspectiva da linguística da enunciação. In: Anais do II Congresso nacional de pesquisas em tradução e interpretação de LIBRAS e língua portugue$s a$, Florianópolis, SC, 2010. Disponível em: http://www.congressotils.com. br/anais.html. Acesso em: 30/03/2012.

FELIPE, Tânia Amaral. LIBRAS em Contexto. Rio de Janeiro: FENEIS, 2005 . A relação sintático-semântica dos verbos e seus argumentos na LIBRAS. Tese de doutorado. UFRJ. Rio de Janeiro, 1998.

. O signo gestual-visual e sua estrutura frasal na LSCB. Dissertação de Mestrado. UFPE. Recife. 1988.

FERREIRA-BRITO, Lucinda. Por uma gramática de línguas de sinais. Rio de Janeiro: Tempo Brasileiro, 1995.

FERREIRA-BRITO, Lucinda. Epistemic, alethic, and deontic modalities in a Brazilian Sign Language. In: FISCHER, Susan D. \& SIPLE, Patricia (Ed.). Theoretical issues in sign languageresearch. v. 1: Linguistics, 224-260. Chicago: University of Chicago Press, 1990.

FLORES, Valdir do Nascimento . Introdução à linguística da enunciação. 2.ed. São Paulo: Contexto, 2010. texto, 2009a.

. et al (Org.). Dicionário de linguística da enunciação. São Paulo: Con. et al. Dicionário de linguística da enunciação. São Paulo: Contexto, $2009 \mathrm{~b}$. . et al. Enunciação e gramática. São Paulo: Contexto, 2008.

FLORES, Valdir do Nascimento; TEXEIRA, Marlene. Introdução à linguística da enunciação. 2.ed. São Paulo: Contexto, 2010. 
GILE, Daniel. Fidelity Assessment in Consecutive Interpretation: An Experiment. Target, 1995b. In: . Consecutive Vs. Simulatenous: Which is more accurate?. Interpretation Studies, No.1, December, p.8-20, 2001.

HERRMANN, Annika; STEINBACH, Markus (Eds.). Nonmanuals in sign language. Amsterdam/Philadelphia: John Benjamins Publishing, 2013.

LYONS, John. Lingua(gem) e Linguística: uma introdução. Rio de Janeiro: LTC, 2013.

METZGER, Melanie. Deconstructing the myth of neutrality. Washigton D.C: GU Press, 2011.

METZGER, Melanie. Sign Language Interpreting: Deconstructing the Myth of Neutrality. Washington, D.C: GU press, 2002.

NAPIER, Jemina; MCKEE, Rachel; GOSWELL, Della. Sign Language Interpreting: theory and practice in Australia and New Zealand. Austrália: The Federation Press, 2006.

PEREIRA, Maria Cristina Pires. Testes de proficiência linguística em línguas de sinais: as possibilidades para os intérpretes de LIBRAS.Dissertação (Mestrado em linguística aplicada) - UNISSINOS, São Leopoldo, 2008.

QUADROS, Ronice Müller de. Phrase Structure of Brazilian Sign Language. Tese de Doutorado - Programa de Pós-graduação em Linguística e Letras. Universidade Católica do Rio Grande do Sul, PUCRS. 1999.

. As categorias vazias pronominais: uma análise alternativa com base na Língua Brasileira de Sinais e reflexos no processo de aquisição. Dissertação de Mestrado - Programa de Pós-graduação em Linguística e Letras. Universidade Católica do Rio Grande do Sul, PUCRS. 1995.

QUADROS, Ronice Müller de; KARNOPP, Lodenir. Lingua de sinais brasileira: estudos lingüísticos. Porto Alegre: Artmed, 2004. 
XAVIER, André Nogueira; WILCOX, Sherman. Necessity and possibility modals in Brazilian Sign Language (LIBRAS). In: Linguistic Typology, 18(3): 2014, p. $449-488$.

ZAVAGLIA, Adriana. Da invariância da linguagem à variância das línguas: contribuição para a elaboração de uma teoria enunciativa da tradução como um caso particular de paráfrase. Tese (Doutorado em Letras) - UNESP, Araraquara, SP, 2002.

Recebido em: 20/06/2015 Aceito em: 28/09/2015 